\title{
Management and Cultural Development
}

\author{
Mohammad Naji \\ Faculty of Human Ecology, Payame Noor University \\ Payame Noor University, Anar, Kerman, Islamic Republic of Iran \\ E-mail: mohammadnaji1356@gmail.com
}

\begin{abstract}
There are the different approaches about the way of achieving to cultural development. Some say that: people and their participation are most important factor in cultural development of a community. In other words, they believe that: a community participation plays very important role in cultural development (Alhagh, 1989). But some believe that: the educational system and technology are more important than people of a community. And they play more important role in cultural development of a community (Asadi, 1990; Etaat, 1999; Nonejad, 1998). In addition to these two above cases, some express that: in this connection, mass media are most important (Legzeian, 2002; Postman, 1992; Zolfaghari, 2004) while from the others point of view, the effect of civil society and non-governmental organizations (NGOs) in cultural development are more important than mass media(Amirahmadi, 1995). Management is another effective factor in cultural development. It has been discussed in some writings of community development and management (Christenson \& Robinson, 1989; Lassey \& Sashkin, 1983; Sariolghalam, 1992; Shatar Sabran, 2003). Overall, although, there are many factors that have the basic role in cultural development but, the management is less under attention globally, especially in developing countries. Therefore, this paper is going to explore the status of management in cultural development. And it explains how management can affect on the cultural development. The purpose of this paper is to explore the role of management in cultural development and outcomes of management's role in cultural development. For investigation of the management role in cultural development, it is necessary to define, management, culture and cultural development terms. Therefore, at first, this paper defines management, culture and cultural development and then, investigates the role of management in cultural development and its outcomes.
\end{abstract}

Keywords: Management, Culture, Development, Cultural Development

\section{Introduction}

In today world, the developed communities emphasizes on the cultural criteria and knowledge element as well as the economic indexes such as per capita income, national gross productions and mortality rate. The culture is created during long years and centuries, the different transformations such as technology, science change culture quickly. A few years ago, we remembered the economic, social and political aspects of the term not cultural aspect; when we were talking about the development. Why? Because, as far as, Mbakogu (2004, p. 42) said; the culture has always played an invisible role in determining our customs, values, moralities. In the current century, some countries around the world, especially, the developed countries discovered the role of culture in development process of community. And, they were going to expand and develop this role in their communities. They concluded that: the cultural development is a basis to the economic, political, social development. And, it also is more sustainable than the other aspects of development. In this case, Azimi (1990, p. 44)says that the gate of economic development is the suitable culture and civilized people not the big factories and buildings. According to him, economic development depends on the cultural independent identity. Without cultural independent identity, any countries can't be developed. Regarding to this case, Rahimi (2001, pp. 138-145) addressed that: the cultural identity and progressive culture are fundamental and essential factors in the sustainable development of communities. He added that: culture is the main factor of sustainable development. And it is the engine of development. Without that, any development plan will not be successful. Thus, cultural development is the essential condition for economic, social, and political development of community. For achieving of this purpose, the various factors and tools are applied. One of these tools and factors is under attention; is management in the recent years. Management can encourage the social groups for more active participation in communities' affaires. Management plays the effective role in the community decisions-making. Management is one of the effective factors in cultural development that has always been entered to this field. Management facilitates the cultural development. In the other hand, cultural development is more accessible with the management. In fact, cultural transformation and development with multi-goals requires to the 
knowledge and technological skills. The management is one of these knowledge and technological skills that is under attention in the countries. At the present time, the most of countries of the world enjoy the management skill as the basic skill for achieving to the development. Due to this reason, these countries pay special attention to management as expander of pluralism. By effective management, people are organized and mobilized towards the common community goals. The peoples' participation rate in community's affairs is based on the management role strictly. In other words, effective management role increases the peoples' participation rate. Now, this question comes up to our mind: what is the important role of management?

\section{Management}

According to Ricketts (1997, p. 4), nearly, researchers have given over 350 definitions of management within the last seventy - five years. The topic of management always was under the attention of communities and countries. In the manner that, Bolden (2004) believes that: several centuries ago, management was under the attention of communities; from the early Greek philosophers such as: Plato and Socrates to the plethora of management and management gurus. Some say that: management is a process. Some express that: management is an art. And, also, some believe that: management is a skill. But, all of them believe that: the community's minorities are leaded towards the community majorities, by the help of management. In today world, the most countries around the world, especially the developed countries apply management for developing of community. Locke and Kirkpatrick (1991, p. 2) express that: management is the process of leading others towards a common goals. According to Clark(1994, p. 25)management is an activity or set of activities. This is observable for others. It occurs in a group, organization or institution involving a manager and followers who willingly affirm to common purposes. And, they work together for achieving of these purposes. Motahari (1985, p. 43)define management as the best technique for mobilizing, organizing, controlling, and utilizing of human capitals. Nahavandi(2006, p. 4) also believes that management is a grouped phenomenon; there can be no managers without followers. Some believe that: management is an art that defies precise definitions. According to them, management is an art that defines precise definitions. Like beauty, the eye of the beholder often determines it. It is recognition, a privilege that is earned by actions, by strength of character and not by position (Campbell, 1997). It was specified; many different definitions on the management have been expressed by the various researchers. But, there are the same components in all definitions on the management. Affecting (existence of powerful and influential person), adoption of effect (existence of follower or followers, existence of group or groups) and situation (existence of a time for executing of authority) are the common components in management definitions. According to above definitions, management is viewed as: a process that affects others. It is powerful and influential. It has follower or followers. It includes a group or groups. And, it looks for a situation for executing of authority. Therefore, it can be concluded that: management is a process that leads the community's people towards common goals and public utilities. With such descriptions, management can play very important role in the cultural development. What is culture? And, what is cultural development?

\section{Culture and Cultural Development}

The "culture" term relates to the eighteenth century. In fact, for the first time, the culture has been used in the eighteenth century in human communities. Culture topic is one of subjects that always were under the attention among the human community. In the recent decade, sociologists, national, international organizations and institutions have stressed on the importance of culture and cultural development role in human communities. For this reason, in the present world, cultural development is necessary and avoidable. And also culture is as main factor for determining of nations fate. If the countries around the world don't pay attention to the culture importance in the development process; development plans will be confronted with the numerous problems. Culture is the set of the beliefs and behaviors of human groups. On the culture definition, Taylor(Varjavand, 1989, pp. 95-96) says that: culture is a term that involves the religion, art, law, moralities, traditions and all things that people of a community obtain. Myers(Varjavand, 1989, pp. 95-96)believes that: culture is heritage of the last people that the present people apply it for formulating of their future. According to Newman and O'Brien (2006, p. 99), Culture consists of all the products of a society that are created over time and shared. There are two kinds of cultures in the human communities: material and non-material. Orum, Riger, and Johnstone(1999, p. 59) say that: material culture refers to all of the tangible objects that society creates or produces including: cities, transportation, and communication systems, weapons, tools, and technology, clothing, food, furniture, and consumer goods. And, a non-material culture refers to realm of idea and knowledge that are intangible including: forms, rules, beliefs, values, myths, and ideologies. From the viewpoint of sociologists and writers, there are the different many components that involves in the material and non-material culture. The components of material and non-material cultures vary from place to place, time to time, society to society, and community to community. But, in the definitions on culture, some components are the same in most of communities. These 
components consist of; values, norms, beliefs, ideologies in the nonmaterial cultures and food, furniture, clothing, architecture, and design in the material cultures. UNESCO(Salehi, 2007, p. 75) has defined culture as set of spiritual, emotional, material, and rational characteristics of society and communities that have been created over time including: literatures, art, life styles, values systems, beliefs, customs, and traditions. Culture compare to an iceberg and the layers of an onion, because it has both tangible and intangible elements. An example of the onion view on the culture is given below.

Altogether, we can define a culture as set of values, norms, beliefs, ideologies, foods, arts, customs, opinions, furniture, clothing, architectures, and designs that the people learn in the societies and communities. people's efforts of communities for renovating and renewing these values, norms, beliefs, ideologies, foods, arts, customs, opinions, furniture, clothing, architectures, and designs is kind of cultural development. In today world, importance of cultural development has forced UNESCO to call the World Decade for Cultural Development in January 1988 at a ceremony in Paris and has designated May 21 as World Day for Cultural Diversity for Dialogue and Development. According to UNESCO's definitions on cultural development, this term embraces the cultural heritage, literatures, music, visual and demonstrative arts, photography, cinema, radio, television, social, and cultural activities, games, nature, and environment. Akrami (1986, p. 37)believed that: the cultural development means the expansion of cultural facilities for all communities' people. The cultural development is basis for new type of economic, industrial, and technological activities. In this case, Salehi(2007, p. 75) added that: the cultural development means increase of power and efficiency of a culture for answering to communities people's cultural, non-material and material needs. Overall, quantitatively, cultural development means the expansion of cultural facilities for all of communities' people equally. And, qualitatively, cultural development means the mental and physical growth and strengthening of communities' people in order to optimal use of the sources and facilities and establishing of the participation. And, it also increases this participation in decisions -making. With these descriptions, cultural development requires to the cultural innovation and creation. If there are not these innovations and creations, cultural development will face to numerous problems and difficulties. Therefore, innovation and creation are the main keys for cultural development and these innovations and creations require to the some tools and conditions. The cultural freedom is a basis and essential condition for these innovations and creations. Management, mass media, civil society, non-governmental organizations (NGOs), educational systems (schools and universities), related organizations are the necessary tools for achieving to these innovations and creations. Among of these tools, management plays more important role in cultural development. Management can prepare the basis and essential conditions for achieving to these innovations and creations in order to achieve to cultural development.

\section{Management and Cultural Development}

Cultural development is basis for economic, social, military, agricultural, health development through promoting and improving of social behaviors. Cultural development improves the human development, reinforces the cultural sovereignty and integration. And it also increases participation, and empowers communities. Despite of these problems, cultural development prepares a basis for knowing of communities' requirements. Cooperation in decisions-making and multilateral participation enforcement are the other components of the cultural development. In the present communities, management is as a potential factor that develops a culture through enjoying of knowledge and science, promoting of skills and experiences, identifying of problems, designing of exact plans, leading of decision-making process, collecting of resources, directing of plans and projects, and applying of operational programs.

Therefore, management is viewed as one of main solutions for success of community development projects including: cultural, social, agricultural, economic, and health projects. In this case, Shatar Sabran(2003, p. 30) believes that: management is being associated with the success and the failure of community development projects. Form viewpoint of Sariolghalam, (1993, p. 91)management has high position in cultural development as well. Because, he believes that: mental dispersion among the communities' people is reflex of mental dispersion among the communities' managers. According to him, (Sariolghalam, 1990, p. 48), the history has shown that: managers' perspective is the most important organizer, enforcer, supporter, and catalyst and motivator of cultural development. Thus, if management can prepare a basis for participating of people in communities' affaires, the people of those communities will cooperate with them by their knowledge, awareness, and skills regarding to enjoyment of golden opportunities, and discovery of the unknown resources. Management can play very important role in cultural development with some characteristics and specifications. These characteristics and specifications are as follows;

1. Having the awareness regarding to the latest day knowledge and information. 
2. Paying attention to all of the groups that exist in a communities including, political, cultural, religion, and social groups.

3. Having the minimum awareness on the culture functions

4. Having the minimum awareness on the cultural functions of a community

5. Acquaintance and respect to the community values, customs, beliefs, and so on

With these characteristics and specifications, a management can play very important role in cultural development as a connecting point between various resources. Management as a connecting point between various resources can enjoy from mass media, community participation, community representatives, governmental and non-governmental organizations, educational system for identifying of the unknown and potential sources, and achieving to the goals of cultural development. The management supporters and consultants are divided to five groups by Christenson, Robinson(1980, p. 87). They include:

1. the professionally trained community-process specialist, who may be a university professor, a chamber of commerce employee, an extension specialist, a church worker, a social welfare worker, or a public health worker.

2. The institutional administrator who directs or guides several field workers.

3. The private planning or development consultant, employed by a professional firm.

4. The consultant who is hired full time by the community to direct planning and development programs, or

5. State or federal representatives assigned to work with a group of communities.

With these supporters and consultants, management can play role in cultural development, on provided that he/ she inform the community's people regarding to his/her plans and their goals. By the help of five hold-consultants and supporters, an effective and successful management can save a community that is in the crisis conditions. For success of management in cultural development process of community, he/she should train the people of communities according to the today knowledge and education, respect to values of community's people, and develop their values, norms, customs, and beliefs. Therefore, the success of cultural development process of community strictly is based on the role of management. If we assume that the rate of management success in a community is $100 \%$, several statuses will appear for cultural development process in that community which are shown in the below table. (Note 2)

With the exact and entire investigation on the above table, it is became specified that the fate of community success is in the hand of management greatly. If we educate the people of a community, cultural development process in that community will take place quickly and if we educate the people of a community in cultural affairs, cultural development rate will double.

Management can play effective role in cultural education of the community's people. As referred above, cultural education increases the rate of achievement of management in cultural development. Thus, management play role in the cultural development directly and indirectly. Management predicts changes and reactions to change and uses from strategies. For the anticipation of change, management should be equipped to some characteristics. In this case, management should be become familiar to a community values, norms, mores, morals, and customs. Management should spend enough time for more understanding of a community values, norms, mores, morals, and customs. Some believe that: management should do more than this. Even, management should develop a community values, norms, mores, morals, and customs while he/she pays attention to the current values, norms, mores, morals, and customs of that community. Now, it is clear that the role of management in cultural development process of a community is not creation of culture rather the role of management in this process is the help to and support of cultural development, transformation, and participation in order to achieve to cultural valuable results. Whereas, management lives in a community and communicate with the people of that community, management can change the community people's insight, perception, and understanding and prepare them for achieving to cultural development through increasing of consciousness, mental transformation.

Stimulation of community people for increasing of participation in cultural affairs, encouragement of elites, validating to cultural innovations, honesty and fairness, having a friendly relationship with others, cultural suitable planning, proper and exact policy -making, cultural education, cultural investment increase, expansion of cultural and scientific researches, increase of cultural awareness, formulation and affirmation of cultural rules, law, and regulations, decentralization in the cultural affairs, protection and support of the cultural productions, expansion of the cultural activities, and more enjoyment of mass media are among of the measures that 
management can do for achieving to the cultural development. Following the above explanations, this question comes up to mind that what are the outcomes of effective management role in cultural development process of community? Doubtlessly, the effective role of management in cultural development process follows some positive outcomes. These outcomes are listed below.

Participation, honesty, charity, chastity, pureness, compassion, courtesy, equal opportunity, freedom, respect to law, social order, job conscience, dutifulness, health, collaboration, friendliness, nobleness, gratitude, helpfulness, conviviality, justice, open-mindedness, sacrifice, safety net for elderly, unemployed, and etc., social unity, celebrity-worship, civic pride, partnership in common goals are among of the outcomes of the effective role of management in cultural development process of community. Except the above outcomes, harmony, enforcement of physical, psychological, power, force, success, friendship, loyalty, neatness, orderliness, efficiency, fitness, orderliness, rationalization, wisdom, individual, achievement, delight of being, self-improvement, friendliness, group, and social authority, evolution of humanity, loyalty, and innovation are the other components of culture that will expand in communities by help of management.

In addition to these outcomes, concern for others, consensus, cooperation, coordination, integration, equality, fairness, fraternity, harmony, oneness of purpose, respect for individuals, cultures, races, service to others, society, spirituality, spirit, teamwork, truth, accountability, accuracy, act on things, honesty, integrity, justice, public access, rationality, tolerance, knowledge, education (right to, need of, value in), genius, intelligence, learning, skill, thinking, thought, wisdom, accomplishment, authority, commitment, courage, decisiveness, determination, direction are the other outcomes of effective role of management in cultural development process of community.

Moreover, in a community, management also promote and reinforce the human determination, social order, empowerment of individual, hardworking, health \& well-being, perseverance, prosperity, regularity, rule of law, legality, self-reliance, perfection, quality of work, service, simplicity, continuous improvement, creativity, discovery, innovation, pioneer, progress, resourcefulness, calmness, quietude, faith, peace, non-violence, security, stability, tranquility as the components of culture.

\section{Conclusion}

Following the above interpretations, it became clear that reinforcement of management is a basis for achieving to the cultural development. It is revealed that if management respect to the communities' values, forms, rules, beliefs, ideologies, he/she can use from human, physical, natural, social capitals in the best manner for achieving to the cultural development. In the other hand, enjoyment of human, physical, natural, social capitals in the best manner is based on the acquaintance and awareness rate of management with the communities' values, forms, rules, beliefs, ideologies. In this case, management recognizes the community's needs, styles, talents, potentialities. And he/she does her/his activities confidently. In such cases, for two reasons, the people of communities help to management in cultural development process of community as well.

1. Their needs and

2. The lack of paradox between management and people.

Following of this community's participation, management can achieve to a cultural suitable programme, policy-making, education, investment, decentralization, pattern-making, and legislation-making. In a community, if management has an effective role, the people of that community will save from anti-values, anti-customs and will achieve to the high quality of life in the social, individual and group levels without any problems.

\section{References}

Akrami, G. (1986). On the Mass Medias Role and Structure (Vol. 1). Tehran: Soruosh.

Christenson, J. A., Robinson, J. W., \& Community Development Society. (1980). Community development in America (1st ed.). Ames, Iowa: Iowa State University Press.

Newman, D. M., \& O'Brien, J. (2006). Sociology: exploring the architecture of everyday life. London: Paul Chapman.

Orum, A. M., Riger, S., \& Johnstone, J. W. C. (1999). Changing societies: essential sociology for our times. Lanham, Md.; Oxford: Rowman \& Littlefield.

Salehi, R. (2007). Contexts and Cultural Theories (Vol. 1). Tehran: Ghoghonus.

Sariolghalam, M. (1990). Fixed Elements of Development. Economic and Political Information, 35, 47-49.

Sariolghalam, M. (1993). International Consensus on Development. Economic and Political Information, 
71-72(7), 91-97.

Shatar Sabran, M. (2003). An Introduction to Community Development and Leadership. Serdang: University Putra Malaysia Press.

Spencer-Oatey, H. (2000). Culturally speaking: managing rapport through talk across cultures. London; New York: Continuum.

Varjavand, P. (1989). Improvement and Development of Cultural Foundation (Vol. 1). Tehran: Sahami Enteshar.

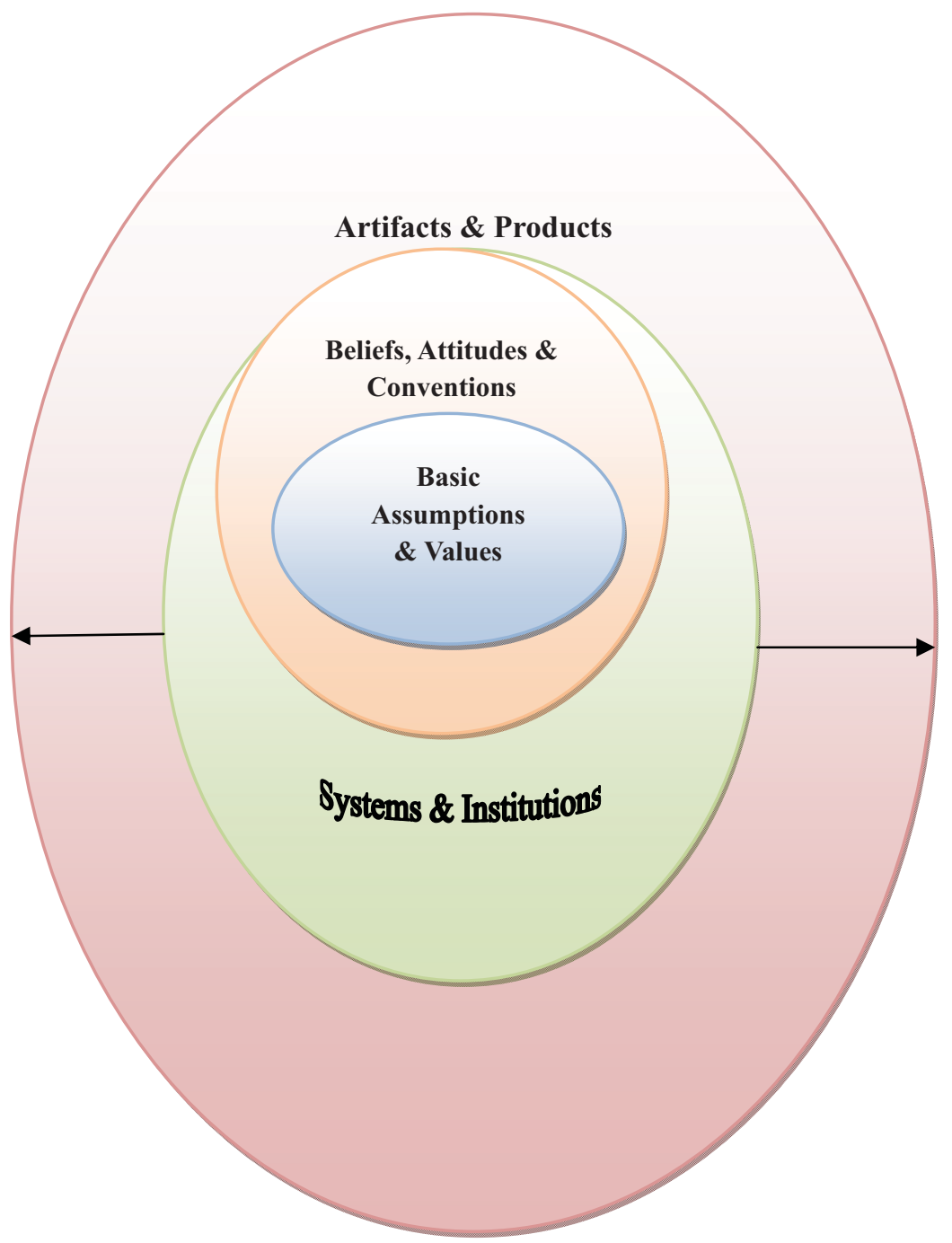

Figure 1. Adapted from Hofstede 1991, and Trompenaars and Hampden-Turner 1997

Note 1: Figure 1 shows manifestations of Culture at Differing Layers of Depth

\begin{tabular}{|c|c|c|}
\hline Management & Community people & Success Rate \\
\hline Agree & Agree & $100 \%$ \\
\hline Agree & Disagree & $80 \%$ \\
\hline Disagree & Agree & $50 \%$ \\
\hline Disagree & Disagree & 0 \\
\hline
\end{tabular}

Note 2: Figure 2 shows the success rate of cultural development process according to management and community's attitudes 